\title{
Prevalence of congenital abnormalities on routine ultrasound scan of second and third trimester pregnancy
}

\author{
Sangita Mahela $^{1 *}$, Bharat Talukdar ${ }^{2}$
}

\author{
${ }^{1}$ Department of Radiology, Fakhruddin Ali Ahmed Medical College, Barpeta, Assam, India \\ ${ }^{2}$ Department of Obstetrics and Gynaecology, Fakhruddin Ali Ahmed Medical College, Barpeta, Assam, India
}

Received: 09 October 2015

Revised: 23 November 2015

Accepted: 14 December 2015

\section{*Correspondence:}

Dr. Sangita Mahela,

E-mail: sangitamahela@gmail.com

Copyright: ( $\odot$ the author(s), publisher and licensee Medip Academy. This is an open-access article distributed under the terms of the Creative Commons Attribution Non-Commercial License, which permits unrestricted non-commercial use, distribution, and reproduction in any medium, provided the original work is properly cited.

\begin{abstract}
Background: Objective of the study was to evaluate the antenatal prevalence of major congenital abnormalities and its pattern.

Methods: This is a cross-sectional study carried out in the department of 'Radiology' at 'Fakhruddin Ali Ahmed Medical College and Hospital', Barpeta. Patients in the 2nd and 3rd trimester of pregnancy, referred to 'Radiology' department from the outpatient and inpatient departments of 'Obstetrics and Gynaecology' were included in the study. Antenatal ultrasound findings were statistically analyzed on structured data collection form.

Results: Total 2650 numbers of 2nd and 3rd trimester prenatal ultrasonography (USG) were done. Out of these 45 numbers of congenital anomalies were detected. The antenatal prevalence of congenital anomalies was $1.73 \%$. The mean maternal age and mean gestational age at diagnosis was 25.5 years $(\mathrm{SD} \pm 6.15)$ and 27 weeks $(\mathrm{SD} \pm 6.42)$ respectively. Central nervous system (CNS) defect was the commonest (42\%), of which maximum number had anencephaly defect i.e. $8(17.78 \%)$ cases.

Conclusions: Antenatal ultrasound is a non-invasive highly sensitive, accurate and cost effective imaging technique which gives good results in experienced hands. It is recommended that the obstetricians should advise regular USG at least at 2 nd trimester.
\end{abstract}

Keywords: Congenital anomaly, $2^{\text {nd }}$ and $3^{\text {rd }}$ trimester USG

\section{INTRODUCTION}

Congenital anomaly (CA) is the structural or functional anomaly (e.g. metabolic disorder) that occurs during intrauterine life and can be identified prenatally, at birth or later in life. These defects of prenatal origin result from defective embryogenesis or intrinsic abnormalities in the development process. Based on the World Health Organization report, about 3 million foetuses and infants are born and 276000 babies die within 4 weeks of birth every year, worldwide, from congenital anomalies. ${ }^{1}$ Worldwide surveys have shown that birth prevalence of congenital anomalies varies greatly from country to country. It is reported about 3\% in the United States, ${ }^{2}$
$2.5 \%$ in India, ${ }^{3}$ and $2 \%$ to $3 \%$ in the United Kingdom. ${ }^{4}$ The prevalence is as low as $1.07 \%$ in Japan and as high as $4.3 \%$ in Taiwan. ${ }^{5}$ These variations of prevalence may be explained by social, racial, ecological, and economical influences. ${ }^{5,6}$ The most prevalent congenital disorders are congenital heart defects, ${ }^{7}$ neural tube defects ${ }^{8}$ and Down syndrome. ${ }^{9}$

There are various investigating tools which are available for diagnosis of congenital abnormalities. Out of these, ultrasound has become an invaluable tool for detection of many foetal abnormalities in the antenatal period. However, recent research found that the foetal structural abnormalities like foetal skull, brain, spine, abdominal 
wall, limbs, stomach and bladder can be detected at 11-14 weeks scan in only $22.3 \%$ of the cases; therefore, a second trimester anomaly scan was suggested in a routine antenatal care to increase the prenatal detection of the foetal defect. ${ }^{10}$ In certain studies, the sensitivity of detection of foetal anomalies, before the 24th week of gestation, was $93 \%$ for the central nervous system, $45.2 \%$ for the circulatory system, $85.2 \%$ for the digestive system, $85.7 \%$ for the urinary system, $84.6 \%$ for the musculoskeletal system and $95.2 \%$ for other anomalies. Therefore, it is suggested that ultrasonography between the 20th and 22nd weeks of pregnancy can detect the majority of congenital anomalies. ${ }^{11}$

So, the overall detection time varies from early to late pregnancy depending upon the gestational age of the foetus in the first antenatal check up. The accuracy of detection of foetal abnormalities depends on various factors like experience of the ultrasongrapher/ ultrasonologist, quality of equipment, and type of malformation.

In India particularly in Northeastern region where the social support system is poor, bringing up a child with mental or physical handicap is a major burden for the parents and family. In cases where primary prevention does not possible, prenatal diagnosis by ultrasound scan provides the next best alternative. In cases where a major structural defect is identified, termination of pregnancy can be offered. The purpose of this study is to evaluate the antenatal prevalence of major congenital anomalies and malformation patterns in our hospital population of Fakhruddin Ali Ahmed Medical College (FAAMC), Barpeta.

\section{METHODS}

This is a cross-sectional study carried out in the department of 'Radiology' at 'Fakhruddin Ali Ahmed Medical College and Hospital', Barpeta. Pregnant women of 2nd and 3rd trimester, referred to 'Radiology' department from the outpatient and inpatient departments of 'Obstetrics and Gynecology' of the same hospital between January 2014 to December 2014 are included in the study. The Radiologist performed all the transabdominal ultrasonography on a 'Siemens Acuson X300' machine using ' $\mathrm{CH}$ 5-2' probe after taking verbal consent from the patient. A questionnaire was used containing the following information e.g. women's age, parity, gravidity, date of last menstrual period. The questionnaire form also included about the result of transabdominal USG examination which included the following: singleton or multiple, dead or alive foetus, gestational age, and presence or absence of congenital anomalies. All the above-mentioned variables along with the detailed anatomical survey at time of scan and demographic variables including gestational age were entered in a database file and analyzed by GraphPad InStat version 3 .

\section{RESULTS}

During the study period of 2014 January to December, a total of 2650 numbers of 2 nd and 3rd trimesters prenatal USG were done. 45 numbers of congenital anomalies were detected among the pregnant women scanned. So, the antenatal prevalence of congenital anomalies was $1.73 \%$. Of the women having congenital abnormalities in the foetus, the majority were between 20-35 years old $(73.33 \%)$ followed by those above 35years $(15.56 \%)$. The mean maternal age at the diagnosis was 25.5 years $(\mathrm{SD} \pm$ $6.15)$. Women who had primary schooling represented $53.33 \%$, with $26.67 \%$ of women were illiterate. Majority women were nullipara $(42.22 \%)$ followed by primipara (31.11\%). 17 cases $(37.78 \%)$ were detected at 3rd trimester and majority at 2 nd trimester ie. 28 cases $(62.22 \%)$. The mean gestational age was 27 weeks $(\mathrm{SD} \pm 6.42)$.

Table 1: Socio-demographic characteristics of anomaly positive group of women $(\mathrm{N}=45)$.

\begin{tabular}{|c|c|c|c|}
\hline Variables & Category & Numbers & Percentage \\
\hline \multirow{3}{*}{$\begin{array}{l}\text { Age in } \\
\text { years }\end{array}$} & $<20$ & 5 & 11.11 \\
\hline & $20-35$ & 33 & 73.33 \\
\hline & $>35$ & 7 & 15.56 \\
\hline \multirow{3}{*}{ Literacy } & Illiterate & 12 & 26.67 \\
\hline & $\begin{array}{l}\text { Primary } \\
\text { schooling }\end{array}$ & 24 & 53.33 \\
\hline & $\begin{array}{l}>\text { Primary } \\
\text { schooling }\end{array}$ & 9 & 20.00 \\
\hline \multirow{2}{*}{ Occupation } & Housewife & 45 & 100 \\
\hline & Service & - & - \\
\hline \multirow{4}{*}{ Parity } & 0 & 19 & 42.22 \\
\hline & 1 & 14 & 31.11 \\
\hline & 2 & 8 & 17.78 \\
\hline & 3 & 4 & 8.89 \\
\hline \multirow{2}{*}{$\begin{array}{l}\text { Gestational } \\
\text { age }\end{array}$} & $2^{\text {nd }}$ trimester & 28 & 62.22 \\
\hline & $3^{\text {rd }}$ trimester & 17 & 37.78 \\
\hline
\end{tabular}

Table 2: Results of USG of anomaly positive group of women $(\mathrm{N}=45)$.

\begin{tabular}{|l|l|l|}
\hline Variables & Numbers & Percentage \\
\hline $\begin{array}{l}\text { Live foetus at time of } \\
\text { scanning }\end{array}$ & 33 & 73.33 \\
\hline $\begin{array}{l}\text { Intra uterine death foetus } \\
\text { at time of scanning }\end{array}$ & 12 & 26.67 \\
\hline Multiple pregnancy & 3 & 6.67 \\
\hline $\begin{array}{l}\text { Multiple anomaly of } \\
\text { foetus }\end{array}$ & 4 & 8.89 \\
\hline
\end{tabular}

The results of USG of study population showed that out of 45 numbers of foetuses with congenital anomaly, 33 cases $(73.33 \%)$ were live at the time of scanning and rest of the 12 cases $(26.67 \%)$ were intrauterine foetal death. Three women $(6.6 \%)$ had twin pregnancy with congenital anomaly of foetuses; out of which two were conjoined 
twins. 4 foetuses had multiple congenital anomalies $(8.8 \%)$

Table 3: Anomalies involving different system $(\mathrm{N}=45)$.

\begin{tabular}{|c|c|c|c|}
\hline Category & $\begin{array}{l}\text { Pattern of } \\
\text { anomaly }\end{array}$ & Number & Percentage \\
\hline \multirow{4}{*}{$\begin{array}{l}\text { Central } \\
\text { nervous } \\
\text { system }\end{array}$} & Hydrocephalus & 4 & \multirow{4}{*}{42.22} \\
\hline & Anencephaly & 8 & \\
\hline & Microcephaly & 2 & \\
\hline & Meningomyoceles & 5 & \\
\hline \multirow{4}{*}{$\begin{array}{l}\text { Gastro- } \\
\text { intestinal }\end{array}$} & Duodenal atresia & 4 & \multirow{4}{*}{22.22} \\
\hline & $\begin{array}{l}\text { Diaphragmatic } \\
\text { hernia }\end{array}$ & 2 & \\
\hline & Omphelocele & 3 & \\
\hline & Gastro schiasis & 1 & \\
\hline \multirow{2}{*}{$\begin{array}{l}\text { Genito- } \\
\text { urinary }\end{array}$} & Polycystic kidney & 2 & \multirow[b]{2}{*}{06.67} \\
\hline & $\begin{array}{l}\text { Pelvi - ureteric } \\
\text { junction obstruction }\end{array}$ & n & \\
\hline $\begin{array}{l}\text { Musculo- } \\
\text { skeletal }\end{array}$ & Skeletal dysplasia & 3 & 06.67 \\
\hline \multirow{4}{*}{ Others } & Hydrops foetalis & 6 & \multirow{4}{*}{22.22} \\
\hline & Conjoined twin & 2 & \\
\hline & Cystic hygroma & 1 & \\
\hline & Down syndrome & 1 & \\
\hline
\end{tabular}

Out of the 45 congenital anomaly foetuses, central nervous system (CNS) defect was the commonest (42\%), of which maximum number had anencephaly defect ie. 8 $(17.78 \%)$ cases. This is followed by Gastro-intestinal (GI) system defect which shared $22.22 \%$ of defect. Within $22.22 \%$ of miscellaneous category of anomaly, most of the cases were hydrops foetalies $6(13.33 \%)$.

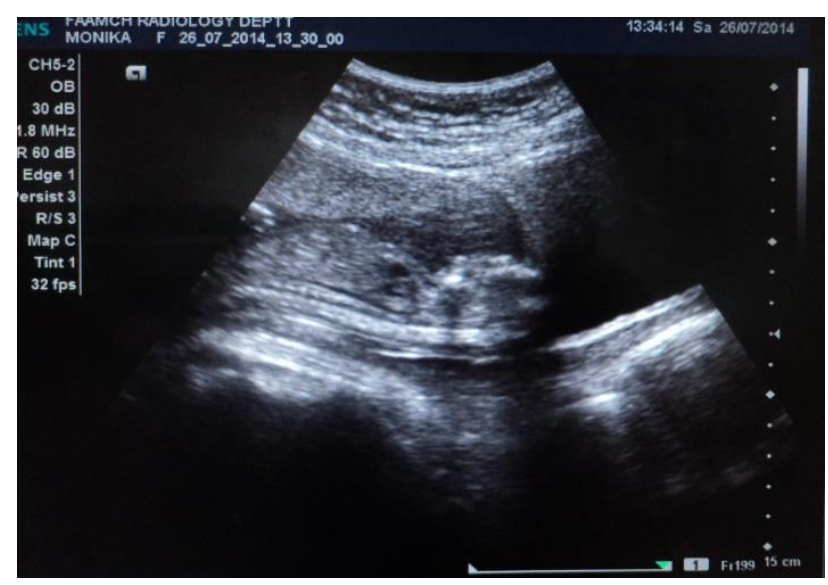

Figure 1: Anencephaly.

\section{DISCUSSION}

Advanced diagnostic technology, especially USG, has made it possible to detect increased number of birth defects in infants antenatally and during the neonatal period. In present study, attempts had been made to find

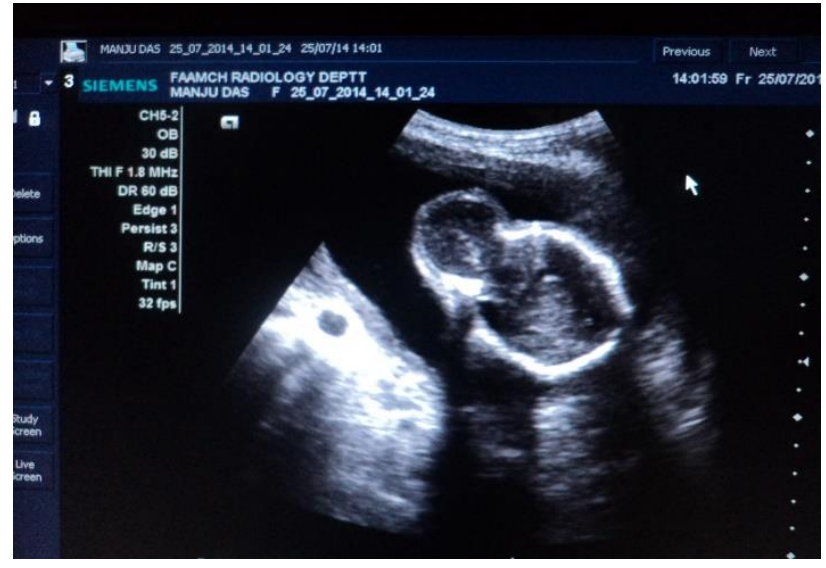

Figure 2: Meningoencephalocele.

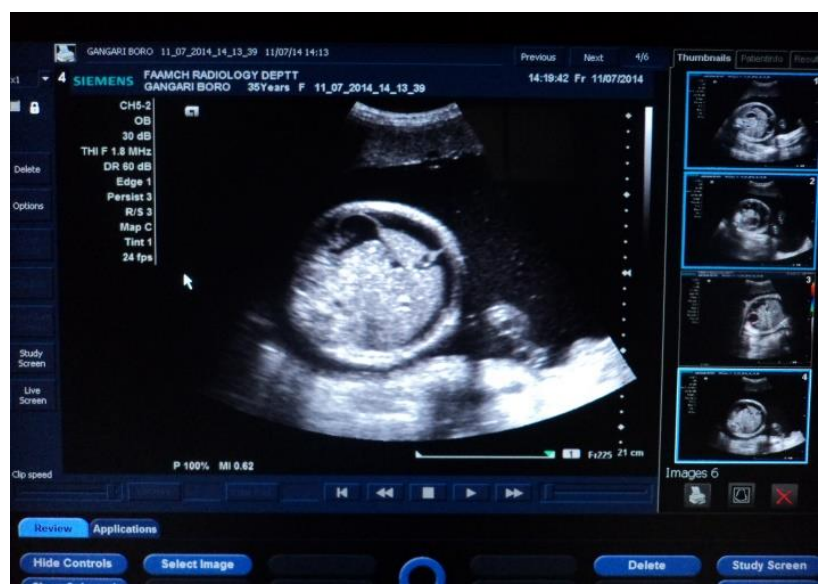

Figure 3: Foetal ascites in hydrops foetalis.

out the antenatal prevalence of anomalies in our hospital who attended for USG in $2^{\text {nd }}$ and $3^{\text {rd }}$ trimester. The antenatal prevalence of congenital malformation in the present study was $1.73 \%$, which is comparable with the observations of Nakling et al (2005) $1.47 \%,{ }^{12}$ Souka et al (2006) $1.21 \% .^{13}$ Higher prevalence was observed some other studies like Sallout et al (2008) $2.96 \%,{ }^{14}$ Alia et al (2010) $2.97 \%,{ }^{15}$ Dolk et al (2010) $2.39 \%{ }^{16}$ and Shah et al (2013) $2.38 \% .^{17}$ On the other hand, Taboo et al $(2012)^{18}$ and Alakananda et al (2015) ${ }^{19}$ showed lower prevalence than the present study. This variation may be due to different geographical area, social factor, racial difference, observer variation and equipment quality. As true prevalence of congenital anomalies depends upon several factors and therefore two studies are never strictly comparable. Though elderly age group and higher parity are considered as risk factors for congenital anomaly, in our study the incidence was observed higher in primigravida and younger age group. ${ }^{20}$ This may be due to earlier age of marriage in our scanning population.

In present study, congenital malformations of the central nervous system were the highest $(42.22 \%)$ followed by malformations of the gastrointestinal system (22.22\%). Similar findings were observed by Agarwal et al (1999) ${ }^{21}$ and Perveen et al (2007). ${ }^{22}$ None of cardiac defects were 
diagnosed in our study. The low detection rate was because the four chamber view was only included in the scan in our study population, and no targeted imaging for foetal anomalies was done.

\section{CONCLUSIONS}

In this study prevalence of fetal congenital anomaly was found to be $1.73 \%$. CNS defect was found to be the commonest form of anomaly in our study population. Creating awareness regarding regular ANC and importance of anomaly scan on time can help in primary prevention of disability and reducing perinatal mortality and morbidity.

Funding: No funding sources Conflict of interest: None declared

Ethical approval: The study was approved by the Institutional Ethics Committee

\section{REFERENCES}

1. WHO. Congenital anomalies, fact sheet. Geneva: WHO. 2015.

2. Canfield MA, Honein MA, Yuskiv N, Xing J, Mai CT, Collins JS et al. National estimates and race/ethnic-specific variation of selected birth defects in the United States, 1999-2001. Birth defects. Res A Clin Mol Teratol. 2006;76(11):747-56.

3. Patel ZM, Adhia RA. Birth defects surveillance study, year 2005. Indian J. Pediatr. 2005;72(6):48991.

4. Boyd PA, Armstrong B, Dolk H, Botting B, Pattenden S, Abramsky L. Congenital anomaly surveillance in Englandascertainment deficiencies in the national system. BMJ. 2005;330(7481):27-31.

5. Temtamy S. A genetic epidemiological study of malformations at birth in Egypt. Eastern Mediterranean Health journal. 1998;4:252-9.

6. Biri A. Birth prevalence and distribution of congenital anomalies in a university hospital. PerinatolDergisi. 2005;13:86-90.

7. Lin AE. Cardiovascular malformations: changes in prevalence and birth status, 1972-1990. American journal of medical genetics. 1999;84:102-10.

8. Centers for Disease C, Prevention. Improved national prevalence estimates for 18 selected major birth defects--United States, 1999-2001. MMWR Morbidity and mortality weekly report. 2006;54:1301-5.

9. Wen SW, Liu S, Joseph KS, Rouleau J, Allen A. Patterns of infant mortality caused by major congenital anomalies. Teratology. 2000;6(5):342-6.

10. Carvalho $\mathrm{MH}$, Brizot ML, Lopes LM, Chiba $\mathrm{CH}$, Miyadahira S, Zugaib M. Detection of fetal structural abnormalities at the 11-14 week ultrasound scan. prenat-diagn. 2002;22(1):1-4.

11. Lee RS, Cendron M, Kinnamon DD, Nguyen HT. Antenatal hydronephrosis as a predictor of postnatal outcome: a meta-analysis. Pediatrics. 2006;118:58693.

12. Nakling J, Backe B. Routine ultrasound screening and detection of congenital anomalies outside a university setting.Acta Obstetricia et Gynecologica Scandinavica. 2005;84(11):1042-8.

13. Souka AP, Pilalis A, Kavalakis I. Screening for major structural abnormalities at the 11- to 14-week ultrasound scan. American Journal of Obstetrics and Gynecology. 2006;194(2):393-6.

14. Sallout BI, Al-Hashan MS, Attyyaa RA. Antenatal diagnosis, prevalence and outcome of major congenital anomalies in Saudi Arabia: a hospital based study. Ann Saudi Med. 2008;28(4):272-6.

15. Alia N, Ahmed I. Congenital anomalies: prevalence of abnormalities in 2nd trimester of pregnancy in Madina teaching hospital, Faisalabad on grey scale ultrasound. JUMDC. 2010;1(1):23-8.

16. Dolk H, Loane M, Garne E. The prevalence of congenital anomalies in Europe. Adv Exp Med Biol. 2010;686:349-64.

17. Shah K, Pensi CA. Study of incidence of congenital anomalies in newborn. Gujrat Medical Journal. 2013;68(2):97-9.

18. Taboo ZAA. Prevalence and risk factors for congenital anomalies in Mosul city. The Iraqi Postgraduate Medical Journal. 2012; 11(40): 458-70.

19. Alakananda, Choudhury SS, Neiting C. A study on prevalence of congenital anomalies of foetuses among pregnant women in a tertiary care hospital and its association with socio-demographic factors. The New Indian Journal of OBGYN. 2015;2(1):4650 .

20. Singh A. Ravinder K, Jammu S. Pattern of Congenital Anomalies in Newborn: A Hospital Based Prospective, Jammu (J\&K)-India. 2009;11:346.

21. Agarwal SS. Neural tube defect: a preventable congenital malformation. Indian Pediatr. 1999;36:643-8.

22. Perveen F, Tyyab S. Frequency and pattern of distribution of congenital anomalies in newborn and associated maternal risk factors. J Coll Physician Surg Pak. 2007;17(6):340-3.

Cite this article as: Mahela S, Talukdar B. Prevalence of congenital abnormalities on routine ultrasound scan of second and third trimester pregnancy. Int J Reprod Contracept Obstet Gynecol 2016;5:182-5. 